
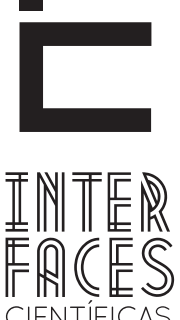

CIENTÍFICAS

HUMANASE SOCIAIS

ISSN IMPRESSO 2316-3348

E-ISSN 2316-3801

DOI - 10.17564/2316-3801.2017v6n2p99-110

\title{
RAÇA, GÊNERO E CLASSE: NOTAS A PARTIR DE EXPERIÊNCIAS DE MULHERES NEGRAS DE CLASSE MÉDIA NA UFMG ${ }^{1}$ \\ RACE, GENDER AND CLASS: NOTES FROM THE EXPERIENCES OF MIDDLE-CLASS BLACK WOMEN AT UFMG RAZA, GÉNERO Y CLASE: NOTAS DE LAS EXPERIENCIAS DE MUJERES NEGRAS DE CLASE MEDIA EN LA UFMG
}

\section{Ricardo Dias de Castro}

Tayane Rogerio Lino ${ }^{3}$

\section{Paula Rita Bacelar Gonzaga²}

Claudia Mayorga

\section{RESUMO}

Esse artigo traz contribuições acerca da complexa trajetória de mulheres negras universitárias de classe média da UFMG e analisa as dinâmicas e vivências de preconceito e discriminação que ocorrem em espaços universitários e economicamente privilegiados. Em uma tentativa de produzir conhecimento com essas entrevistadas, construímos narrativas a partir de conversas realizadas com quatro mulheres negras de classe média com trajetórias universitárias na UFMG. Observamos, a partir da fala das entrevistadas, que a ascensão econômica e o acesso ao dinheiro não eliminam o racismo e, por outro lado, acionam-no de distin- tas maneiras. Em linhas gerais, as jovens denunciam e constroem distintos modos de combater a sua solidão/ exotificação no mercado afetivo-sexual; os conflitos inter-raciais com homens brancos e a desvalorização de seus saberes, culturas e práticas afroreferenciados.

\section{PALAVRAS-CHAVE}

Raça. Gênero. Preconceito. Classe Média Negra. Universidade. 


\section{ABSTRACT}

This article offers contributions about the complex trajectory of university middle-class black women from UFMG shed light on the dynamics and experiences of prejudice and discrimination which occur at the university and economically privileged spaces. In an attempt to produce knowledge with these subjects, we constructed narratives from conversations with four middle-class black women from UFMG. From the subject's speech, we observe that economic ascent and access to money do not eliminate racism and, on the other hand, trigger it in different ways. In gener- al terms, the girls denounce and construct different ways of combating their solitude/to become exotic in the affective-sexual market; interracial conflicts with white men, and the devaluation of their knowledge, cultures and afro-referenced practices.

\section{KEYWORDS}

Race. Gender. Prejudice. Black middle class. University.

\section{RESUMEN}

Este artículo ofrece contribuciones sobre la compleja trayectoria de mujeres negras de clase media universitaria de UFMG para dar luz acerca de dinámica y las experiencias de prejuicio y discriminación que se producen en la universidad y en los espacios económicamente privilegiados. En un intento de producir conocimiento sobre estos temas, construimos relatos de conversaciones con cuatro mujeres negras de clase media de UFMG. A partir de los discursos, observamos que el ascenso económico y el acceso al dinero no eliminan el racismo y, por otro lado, lo desencadenan de diferentes maneras. En términos generales, estas mujeres denuncian y construyen distintos modos de combatir su soledad o su tipificación como exótica en el mercado afectivo-sexual; los conflictos interraciales con los hombres blancos y la devaluación de sus conocimientos, culturas y prácticas afro-referenciadas.

\section{PALABRAS CLAVE}

Raza. Género. Prejuicio. Clase media negra. Universidad. 


\section{INTRODUÇÃO: DELINEANDO UMA PERGUNTA- -PROBLEMA}

Atualmente, o cenário político e institucional das relações raciais, no Brasil, não é o de anos atrás. Se em um período da história do país seria impossível a existência de negros com privilégios econômicos; hoje, essa experiência não só é possível como tem se tornado um problema de pesquisa para as Ciências humanas nacional e internacional (FIGUEIREDO; FURTADO, 2014; FIGUEIREDO, 2002, 2012; SANTANA, 2014). Nessa direção, os estudos sobre raça e racismo deixaram de ser, apenas, uma forma de denúncia e produção de resistências de um sujeito negro universal e começam a se interseccionar com marcadores sociais diversos que, também, hierarquizam experiências outras; assim como é o gênero (CRENSHAW, 2004).

O gênero, nesse sentido é uma categoria de análise fundamental visto que desvela um sistema de poder hierárquico que fomenta as desigualdades historicamente construídas entre homens e mulheres e se legitimam nos pensamentos, práticas e instituições sociais (SCOTT, 2016). Para além do gênero; o lugar e a experiência das mulheres negras é uma perspectiva necessária para se pensar uma produção de conhecimento engajada no descortinamento do racismo e do patriarcado brasileiro e nas possibilidades de seu combate.

A denúncia da dupla ou tripla opressão - quando consideramos a classe - que se inscreve nas vida e corpos das mulheres negras na sociedade brasileira é, ainda, um campo de disputa de teóricas do feminismo negro, militantes, acadêmicas que apontam as incoerências tanto do movimento feminista hegemônico como do movimento negro (CARNEIRO, 1995; GONZALES, 1983).

Diante desse cenário, esse artigo é resultado da pesquisa de mestrado intitulada "Pertencimento Racial de Universitários Negros de Classe Média da UFMG" que se debruçou sobre a trajetória de universitários negros de classe média de uma das principais Universidades Federais do Brasil. Ao longo do proces- so investigativo precisamos atentar para as diferenças/desigualdades entre as trajetórias dos homens e das mulheres negras universitárias. Ora, a intersecção entre o patriarcado e o racismo compõe um cenário que se propõe a regular e valorar seus corpos, afetos, cabelos, estéticas, racionalidade, intelectualidade sexualidade, seus corpos e produz efeitos, historicamente silenciados e invisibilizados, na subjetividade dessas mulheres. Esse contexto, simbolicamente violento fomenta ainda que as mulheres negras sejam a maioria das que sofrem com outros tipos de violência.

\begin{abstract}
Em relação ao tópico da violência, as mulheres negras realçaram uma outra dimensão do problema. Tem-se reiterado que, para além da problemática da violência doméstica e sexual que atingem as mulheres de todos os grupos raciais e classes sociais, há uma forma específica de violência que constrange o direito à imagem ou a uma representação positiva, limita as possibilidades de encontro no mercado afetivo, inibe ou compromete o pleno exercício da sexualidade pelo peso dos estigmas seculares, cerceia o acesso ao trabalho, arrefece as aspirações e rebaixa a autoestima. Esses são os efeitos da hegemonia da 'branquitude' no imaginário social e nas relações sociais concretas. É uma violência invisível que contrai saldos negativos para a subjetividade das mulheres negras, resvalando na afetividade e sexualidade destas. (CARNEIRO, 2003. p. 122).
\end{abstract}

Nessa direção, foi inevitável que nos interrogássemos sobre como a experiência de ser mulher negra e possuir privilégios econômicos - e, nesse caso, privilégios acadêmico-educacionais - operam na subjetivação e na existência dessas sujeitas na sociedade/ universidade. Como é o racismo nesses espaços médios e intelectuais a partir do lugar das negras universitárias de classe média? Como essas jovens resistem às cenas de preconceito e discriminação que sofrem em seus cotidianos? Como o racismo e o sexismo se refinam em contextos produção de conhecimento e espaços universitários no Brasil? 


\section{AS MULHERES NEGRAS UNIVERSITÁRIAS DE CLASSE MÉDIA E OS DESAFIOS DA INTELECTUALIDADE: ENTRE SUBALTERNIZACÕES E RESISTÊNCIAS}

Nas últimas duas décadas é possível identificar a presença de um grupo de negros, homens e mulheres, que passaram a fazer parte de uma classe média negra. Constata-se que as estratégias de ascensão utilizadas pelos negros têm sido a escolaridade elevada e a associação entre emprego público e privado, bem como a importância do investimento e do apoio familiar nas suas trajetórias ascensionais (FIGUEIREDO; FURTADO, 2014; SANTANA, 2014). No que se refere ao casamento inter-racial, ele parece operar como uma estratégia de "consolidação do status social, mais do que um mecanismo de mobilidade; já que o casamento parece ser postergado até à melhoria da condição econômica dos negros" (FIGUEIREDO, 2002; FIGUEIREDO, 2012; FIGUEIREDO; FURTADO, 2014, p.141).

Tais estratégias de mobilidade econômica circulam entre um grande investimento na educação, pelo emprego público (garantia do mérito individual), pelo apoio da rede familiar e, acima de tudo, por escolhas cuidadosas - negros não podem se dar ao luxo -, dentro das reais possibilidades de êxito. Com isso queremos dizer as escolhas afetivas, sexuais e profissionais da maioria dos sujeitos negros não pode ser feita sem que isso se vincule a um projeto coletivo maior e de estabilidade financeira.

Algumas famílias negras, por exemplo, atendendo ao projeto coletivo do sonho da classe média, complementam a renda mensal familiar, executando serviços, no próprio lar, ou dobrando horas de trabalho; de modo que todo o apoio possível à educação dos filhos possa ser uma realidade. Os filhos com melhores rendimentos seriam aqueles a receber mais investimento, valendo-se da escola como um espaço de luta pela apropriação do capital cultural (SANTANA, 2014).
É sabido que a ascensão econômica dos negros não lhes garante idêntica possibilidade de que usufruem as pessoas brancas. Ou seja, não há bom salário, mérito, qualificação e nem status profissional que garanta a integração do negro na socialização/aceitação de brancos. Isso porque não há um caminho linear entre ganhar dinheiro e ser branco, o que, por conseguinte torna os negros ascendidos "fora do lugar". "Ao sujeito negro não adianta ter educação, casas de tijolo e ascensão social, pois quando adquirir tudo isto, a raça será o fator de interdição do sujeito a este grupo da elite" (SCHUCMAN, 2012, p. 97).

Ainda assim, os processos de mobilidade econômica e das dinâmicas de preconceito e discriminação, são distintos para homens e mulheres marcados pela negritude. Nessa direção, é importante escother uma forma de olhar para esses problemas que tencione e reconheça que os marcadores de gênero e raça criam outros impeditivos e distintas trajetórias e vivências para os negros e as negras, universitários de classe média.

A articulação do racismo com o patriarcado tem criado lugares e posições muito perversas para as mulheres negras, que em função do pacto narcísico branco da elite - pacto esse estruturado na negação do racismo e pela desresponsabilização dos brancos pela sua manutenção - são alijadas dos acessos econômicos, políticos e educacionais-intelectuais desse país (BENTO, 2002). Perguntamo-nos, nesse contexto como essas mulheres, marcadas pela desumanização com que o discurso colonial e escravocrata thes denominou historicamente, conseguem romper com os estereótipos de hipersexualização, bestialidade e irracionalidade que ainda hoje vigoram sobre ela?

Ao longo da história, a organização social, econômica e política do mundo - a partir do privilégio da masculinidade - teve como efeito a localização das mulheres em determinados espaços que limitam as suas potências dentro da esfera do cuidado, da maternagem e dos afazeres domésticos (GONZAGA, 2015). O sistema de poder racista, engendrado ao sistema de poder patriarcal, parece complexificar, nessa idêntica direção, as relações violentas que recaem sobre as 
mulheres negras; subalternizadas em sua experiência de ser mulher e de ser negra.

Vejamos: o mito da democracia racial - crença de que o Brasil é o palco de uma relação harmônica entre distintos grupos raciais e culturais - oculta algo para além do que mostra, exercendo sua violência simbólica de maneira especial sobre a mulher negra (GONZALES, 1983). A história que esse mito não revela é a história da formação de um povo a partir do estupro sistemático de mulheres negras, concebidas como patrimônio de seus senhores; de mulheres indígenas, lidas pelo projeto colonial como corpos disponíveis que desafiavam a moral cristã. É a história da transposição dessas mulheres de objetos a algozes, o mito da democracia racial coloca as mulheres não brancas, mulheres violentadas no contexto colonial, como seres bestializados e hiperssexualizados, seres não humanos.

Gonzales (1983) ajuda-nos a compreender uma chave analítica importante: uma espécie de um paradigma da (des)humanidade das mulheres negras que têm se materializado em três personagens do nosso imaginário social: a mãe preta que, embebida, em uma atmosfera de bondade e ternura, é boa cozinheira e boa cuidadora; mas não, exatamente, um exemplo de beleza. A doméstica: "quanto à doméstica, ela nada mais é do que a mucama permitida, a da prestação de bens e serviços, ou seja, o burro de carga que carrega sua família e a dos outros nas costas. Daí, ela ser o lado oposto da exaltação; porque está no cotidiano." (GONZALES, 1983, p. 230).

E a mulata que, por fim, nada mais é do que a empregada vista a partir de sua sexualidade exaltada e “natural” sedução a serviço dos desejos dos homens. Hooks (1995) denuncia a concomitância que a formação de figuras centradas no corpo (grande habilidade e força física, hiperssexualização, irracionalidade, bestialidade) cumpre com a função de negar reconhecimento às potencialidades intelectuais das mulheres negras, impossibilitando seus acessos educacionais, produzindo nelas a ideia de que o campo da produção de conhecimento não lhes pertence.

A desqualificação das mulheres negras, seus pertencimentos culturais, étnicos, econômicos se reflete nas narrativas que analisamos neste trabalho, como nos narra Maria sobre um momento em que esteve reunida com amigos em uma festa na casa de uma colega do seu núcleo de pesquisa. Nesse momento, escuta e canta uma música da Raça Negra na presença de mais outros dois amigos negros (de origem popular).

\begin{abstract}
Maria: Aí uma menina do laboratório virou para mim e falou assim "Nossa Maria, você canta esse tipo de música? Se eu não te conhecesse, se eu não soubesse quem você é, eu ia ficar meio chocada com tudo isso. Eu não ia te achar uma pessoa inteligente [...] Eu senti uma angústia muito grande dentro de mim. [...] Escutar Raça Negra quer dizer que você é burro? [...] E ela gosta, e ela banca que gosta de escutar Los Hermanos ne. Caetano Veloso. Ok, são coisas maravilhosas, mas uma coisa não quer dizer que um é inteligente e o outro é burro. Na hora que ela falou aquilo é como se tivesse cutucado a minha origem. É como se tivesse cutucado a minha família.
\end{abstract}

É sabido sobre as tensões que existem em torno da relação entre as produções culturais negras e os efeitos que elas possuem na construção de hierarquias entre as artes e os artistas (BORGES, 2012; LEAL, 2012; MEDEIROS, 2006). Precisamos nos atentar, nessa direção, para como os estilos musicais, assim como todo e qualquer elemento social, lidos sobre lentes antirracistas, apontam para uma valoração entre altas e baixas culturas que parecem acompanhar o lugar e a história de origem desses estilos.

Quanto mais um estilo musical se aproxima de uma construção ocidental, europeia e branca; mas ela é vista com requinte, rebuscamento, classe, elegância e qualidade. No sentido contrário, as produções artístico-culturais engajadas e protagonizadas pela juventude negra das periferias urbanas tendem ser criminalizadas e negadas como produções culturais legítimas; sendo, muitas vezes, tratadas pela crítica brasileira como gêneros de baixa qualidade.

A instituição do ensino superior foi construída sobre essa dicotomia entre os que têm gostos/valores/ saberes reconhecidos como superiores - e por superiores leia-se brancos - e por outro lado pela subalternização dos povos negros que foram alijados da 
construção intelectual e da participação desses espaços de prestígio sócio-cultural-econômico das elites ditas modernas. O lugar que o projeto eurocentrado e moderno de universidade reservava à população negra eram aqueles onde estes exerceriam funções de limpeza e manutenção, com os menores salários do corpo de funcionários nestas instituições e com condições precarizadas de trabalho.

Assim, a fala da colega de Maria "eu não te acharia inteligente" é a reprodução do repertório da intelectualidade racista brasileira que entende que apenas assimilando os gostos/valores/saberes brancocentrados negros podem ser inteligentes. Ainda que esse projeto hegemônico (branco, patriarcal e elitista) perdure enquanto discurso e modos de institucionalização dos espaços de poder e privilégio que existem no Brasil; há grupos que, historicamente, excluídos da universidade, tem-na acessado em tempos atuais.

O número de negras e negros no espaço da universidade tem aumentado, sobretudo pela implementação de políticas de ação afirmativa. Sendo assim, essa instituição vem lidando com um espaço em que antes, a negritude tinha um lugar apenas marginalizado. Com isso, queremos dizer que têm ocorrido mudanças estruturais e culturais - com uma maior utilização e comercialização de símbolos e produtos da denominada cultura afro-brasileira - bem como toda uma institucionalização em torno de medidas racialmente democráticas - como as reservas de vagas nas universidades públicas - que possibilitam esses processos de mobilidade para além do desejo de embraquecimento dos negros (FIGUEIREDO, 2002).

Esse cenário possibilita um rol de condições que ajudam na diminuição da distância entre ser negro e ocupar posições mais valorizadas na hierarquia social; como no mercado de consumo, no acesso a bens culturais e simbólicos e ao capital intelectual (FIGUEIREDO, 2002). Nessa direção, como as universitárias negras - outrora, apenas, associadas às mais diversas carências (econômicas, culturais, materiais, estéticas e simbólicas) - coparticipam da construção desse novo momento histórico da sociedade? As ações afirmativas têm sido um dispositivo de fortificação na trajetória dessas jovens? (FERES JÚNIOR; DAFLON, 2015).

Ainda que esse projeto de sociedade racista e patriarcal, de fato, construa uma dinâmica que estruturaliza e subjetiva a experiência das mulheres negras, hoje, essas mulheres podem responder a sociedade a partir de outros lugares que não esses, histórico e subalternamente prescritos. Mulheres negras têm, ainda que escassamente, ocupado espaços de privilégio econômico, intelectual o que tem como desdobramento, um novo imaginário social acerca das negras em ascensão, o que torna a pergunta sobre essas mulheres um problema para o pensamento social implicado em um debate feminista e antirracista (DAVIS, 2016). O que temos a dizer sobre as jovens pretas que, longe dos estereótipos das mulatas do carnaval, constroem as suas trajetórias em torno de projetos de vidas acadêmicos e intelectuais no ensino superior público?

\section{PROCESSOS METODOLÓGICOS}

Esta pesquisa adota uma perspectiva feminista de investigação e para tal defende a ideia de uma construção de ciência que não seja regida pela neutralidade e pela objetividade. Muito pelo contrário, explicitamos, aqui, a nossa intenção e submersão humana em todo o processo de lapidação desse problema de pesquisa. Desde as ideias iniciais e delineamento de uma interrogação válida para a ciência; até a sua explicitação nesse formato escrito que nossos interlocutores têm em mãos (MAYORGA, 2014; SILVA; GOMES; GRAÇA; QUEIRÓS, 2005)

Dentro desse contexto, fizemos usos das narrativas como sendo ao mesmo tempo uma proposta epistemológica, teórica e metodológica (no sentido do procedimento) para a realização de uma pesquisa interessada em investigar dinâmicas invisíveis e complexas; carregadas de atravessamentos políticos e não ditos. Nesse sentido, as narrativas são potentes discursos que lidam com a ação e a intencionalidade humana quando essa é colocada em relação com o 
culturalmente previsto. Ou seja, ela é efeito da relação entre a estrutura social e o mundo idiossincrático dos desejos, das crenças e das esperanças. Sendo assim, ao contarem as suas histórias, os indivíduos não pretendem, somente, memorizar e reelaborar suas experiências: eles, também pretendem, explicitamente, posicionar-se diante de suas histórias; convencendo, persuadindo e impressionando os seus interlocutores (CARVALHO, 2003; FONTE, 2006).

0 problema da classe média negra universitária, portanto, coloca-nos diante de vieses teóricos e políticos, haja vista a forma como o racismo brasileiro opera em toda a sua complexidade, invisibilidade, ambiguidade e militância. As mulheres de pesquisa, aqui, encontram-se em constante construção pela sua socialização nas famílias, nas instituições e nos amplos discursos colocados em torno de suas experiências. Separar esses elementos, certamente, despolitizaria essas trajetórias e, por isso, a construção das narrativas pareceu-nos uma escolha acertada para o nosso problema.

Nessa direção, para a coleta e interpretação dos dados, para este artigo, lançamos mão da construção das narrativas com quatro entrevistadas negras, com trajetórias acadêmicas numa instituição federal de ensino superior, autodeclaradas pretas - de distintos campos e áreas de conhecimento e atuação em cursos da graduação e da pós-graduação - e que foram convidadas a falar da/pela/para/contra a classe média/ classe média negra de modo amplo². Organizamos as suas falas, posteriormente, em diversas categorias de análise. Aqui, traremos aquelas falas que tangem o recorte desse artigo: as interseções entre gênero, raça e classe.

É essencial dizer que, apesar de se considerar o racismo, patriarcado e classismo como sistemas de poder estruturais, definitivamente, não os entendemos como lógicas estanques. Sobretudo, vemo-los como estruturas porosas e desestabilizadas pelas dinâmicas contra-hegemônicas da própria sociedade e, principalmente, pelas mulheres negras. Dessa maneira,

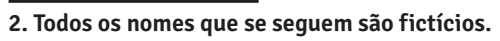

estamos falando de cenários complexos, permeados por questões simultâneas e paradoxais, que carregam um histórico naturalizado de subalternizações, tanto quanto brechas para novos projetos subjetivos e societários.

\section{ASVÁRIASFORMASDERACISMOERESISTÊNCIA DAS NEGRAS UNIVERSITÁRIAS DE CLASSE MÉDIA}

Em relação à posição das mulheres negras no mercado afetivo-sexual, definitivamente, percebemos uma desvantagem das pretas na construção de uma trajetória satisfatória nesse quesito. Algo que já foi apontado como um efeito comum na vida de jovens negras, independentemente, da classe social (SOUZA, 2008).

\begin{abstract}
Nilma: Ah, tem aquela fase também na escola que eles fazem aquela lista da escola de beleza, aí você nunca tá, a lista da menina mais bonita e você nunca tá porque você não é o padrão.

Benedita: No ensino médio já começou a ficar complicado, porque aquela época que começa assim "ahh, fulano quer ficar com ciclano". Sabe, esse tipo de coisa. E tipo ninguém queria ficar comigo. [...] Chegava na festa junina eu nunca tinha par. [...]. Assim eu sabia que eu era diferente, assim que eu tinha uma cor de pele diferente das outras pessoas. Que eu tinha um cabelo que eu odiava, que meu sonho era que meu cabelo fosse liso.

Maria: Eu era a pessoa que dedicava, estudava e tirava as melhores notas e era a pessoa que era amiga da galera. Mas não era a mais bonita ne, não era o cabelo mais bonito. [...] E o meu grupo nessa escola particular, era o grupo dos excluídos [...] tinha uma pessoa que era a pessoa gordinha da sala [...] tinha uma com fenótipo um pouco mais de índia.
\end{abstract}

Nilma nunca ganhou o prêmio de beleza da escola, Benedita não consegue um par para a dança e Maria fala sobre isso ao dizer que ela não poderia compor o grupo popular da escola por não pertencer a ele fenotípico-esteticamente. Com isso queremos dizer que as alianças intra-grupais, envolvendo os sujeitos brancos 
são forjadas no antagonismo com sujeitos negros. A não presença de sujeitas negras nos concursos de beleza, com pares nas danças e nas rodinhas das patricinhas e dos playboys brancos é comumente justificada por afinidade e interesses individuais (gostos e estilos musicais, por exemplo) e, dificilmente, por tensões e conflitos raciais. Esse nos parece ser um bom exemplo de como a branquitude se consolida pela negação de um problema sócio-racial e pela constante interdição do povo negro em espaços de poder pelo esforço na direção de sua exclusão estética, afetiva, moral econômica e política (SKIDMORE, 2013).

Por outro lado, quando essas mulheres negras são vistas como objeto de desejo e reconhecidas como possíveis parceiras sexuais, elas, imediatamente, são colocadas dentro de um espectro de um corpo que deve atender às demandas sexuais dos homens.

Dandara: Enquanto mulher negra eu era um sujeito de desejo, de cobiça, nunca de fala, [...] acolhimento, nunca de demanda, sabe? 0 único lugar que eu cabia era de ser a pretinha bonita desse curso, eu não era outra coisa.

Maria: Não posso negar, na graduação, eu tive por um tempo o apelido de globeleza. [...] Justamente não só pela cor, mas muito pelo samba. [...] Então assim eu tive esse tipo de coisa, mas ficava assim ne, globeleza ponto final, morreu. Não era o interesse dos meninos.

Fora da cena do samba e, no cotidiano regular, Maria reafirma o seu desencontro com os padrões estéticos e de sedução (empregada doméstica); mas é reconhecida no lugar de globeleza (racialmente reconhecida e, por conseguinte, degradada) quando o samba a coloca na roda. 0 desejo, aqui, não parece ser construído em torno das inúmeras potências das mulheres negras; mas de uma pressuposta e natural inclinação para práticas sexuais animalescas, violentas (CORRÊA, 2010).

Ainda sobre a crença nesse discurso de uma sexualidade exacerbada, Benedita narra sobre uma experiência em um local turístico da cidade de Belém, no Pará; no qual é confundida com prostitutas da cidade quando estava na companhia do seu atual companheiro branco.
Benedita: Passava cara, sentava ao meu lado, encostava no meu braço. [...] Então, assim, eu achava que eles me achavam prostituta, porque lá tem muitas prostitutas que circulam. [...] Lógico, uma mulher negra com homem branco. Então só pode ser uma prostituta. [...] Eu estava sentada com o (namorado) e tinha um cara tipo atrás dele me dando tchauzinho e mandando beijo.

A perpetração de discursos e estereótipos que reduzem as mulheres negras a figuras animalizadas, seja pela força física ou pela sexualidade, possibilita que Benedita seja alvo de assédio, até em espaços públicos, turísticos, ali Benedita era admitida um corpo exposição, sua inserção acadêmica, seus privilégios econômicos, seus acessos não são cogitados, reduzir ao corpo é desumanizar os indivíduos, negar os afetos, a singularidade, a racionalidade. Nessa direção, a entrada no universo do flerte e no campo do desejo afetivo-sexual é marcada por tensões que nos evidenciam o preterimento da mulher negra como uma companheira passível de ser assumida publicamente junto aos seus parceiros como objeto de amor. Benedita retoma uma história de seu passado com outro rapaz branco que se relacionava com mulheres negras de forma sigilosa.

Benedita: Ele era branco. E eu fui descobrindo depois
que ele já tinha relacionado com várias meninas ne-
gras que eu conhecia. [...] eu saia com ele e nunca saia
com os amigos dele. Nunca conheci ninguém da famí-
lia dele [...] Era sempre assim, "vamos sair só nós dois"
[...] uns lugares assim que o círculo social dele não ia
estar [...] ele começou a namorar uma menina branca
e loura. Passou assim dois meses e já tinha foto dela e
dele no meio da família dele. E assim não tem nem um
ano e ele já está noivo, umas coisas assim, sabe?

A experiência de Benedita no campo afetivo-sexual corrobora as análises de Pacheco (2013), com mutheres negras na cidade de Salvador, que relataram como o preterimento marca suas trajetórias afetivo-sexuais. Benedita narra, em seguida, sobre seu atual companheiro branco; que ela avalia como sendo uma relação saudável; mas que, ainda assim, coloca-a em uma angustiante autorreflexão. 
Benedita: E eu comecei a pensar, gente será que é isso? Será que na verdade, no meu subconsciente, eu não sei, eu não estou percebendo, eu estou com ele como uma forma de aceitação para eu ascender? $\mathrm{E}$ comecei a me perguntar isso e comecei a ficar assim muito mal.

As relações inter-raciais parecem fugir do padrão das relações nas quais a paridade racial neutraliza diferenças e desigualdades. Longe das prescrições das relações amorosas ideais em que os conflitos não aparecem como um elemento da relação; Benedita assume o fato de que ter um parceiro branco implica uma série de negociações, conversas e reposicionamentos ao casal. Ou seja, ao assumir o namoro com um rapaz branco da classe média, Benedita se questiona sobre as possibilidades e os limites de seu próprio desejo afetivo-sexual.

Questionando-se, sobretudo, quanto à razão do seu interesse por um homem branco para além de um desejo que se explique, apenas, pelo prazer de uma relação amorosa Benedita começa a se interrogar não só sobre o seu desejo, mas, também, sobre a função e a intenção do seu desejo ao assumir uma relação pública com um homem branco da classe média: miscigenar uma possível prole? Estar com alguém que possibilite acessos e privilégios, na sua trajetória, a partir de agora?

Benedita: Todos os homens que eu... que passaram pela minha vida, poucos eram homens assim, que me respeitavam e tudo mais. Ele foi um desses que também me respeitou sabe. Ai eu comecei assim, será que eu estou com ele só porque ele me respeita? [...] Ai começou a vir assim um monte de pensamentos assim no início. Pensei em terminar, pensei em dar um tempo. Ai eu fui organizando meus pensamentos, a gente continua junto, mas tem coisa ainda que eu fico pensando, sabe? Assim eu gosto muito dele, amo ele, a gente dá super certo, tudo bate, só que eu fico com isso na cabeça ainda. [...].

A experiência do preterimento permite que Benedita questione a ideia do desejo como natural e veja a si própria como possível reprodutora da lógica racista que, em muitos momentos, contribuiu para que ela não fosse apresentada a familiares e amigos de seus namorados ou que fosse reduzida a um objeto sexual.

Em contrapartida, todo discurso antirracista político e mais, publicamente, colocado tem se esforçado na direção da produção de discursos afirmativos da beleza dos negros. 0 elemento estético, aqui, se junta à representação da intelectualidade de uma ativista/ acadêmica de referência do feminismo negro e da ex- primeira dama dos Estados Unidos da América, Michele Obama.

Dandara: por isso que a gente tem que ser coerente com o que a gente fala mesmo, [...] alguns vão incomodar, mas outros vão identificar e esse te dá um sentimento tão bom, de "nossa, que legal que outra pessoa te ver de outra forma”, e essa menina (que andava na rua) ela me viu como se eu fosse uma pop star. [...] Eu era a Angela Davis.

Maria: Tem uma pessoa que trabalha, não diretamente comigo, mas ela trabalha no laboratório do lado, ela tem black, ela é negra e ela... assim todo mundo fica apaixonada forma que ela chega na universidade. Gente, como é que pode ser tão elegante, ser tão bonita. Então ela já é o perfil de beleza né. Aquela pessoa politizada. Então muda muito assim na pós-graduação eu já definitivamente não sinto que eu não sou o padrão de beleza, já sinto encaixada. [...] Eu já me sinto dentro de um padrão de beleza. E o pessoal do meu laboratório gosta muito de falar que eu sou diva. É... eles me chamam de Michele Obama. Então é Michele pra cá, é diva para lá. Então assim eu já consigo ter a autoestima de quem eu sou.

O Black Power - símbolo histórico de resistência dos negros e que reiteradas vezes aparece como elemento comum da fealdade natural dos afrodescendentes em discursos racistas - aparece como uma ligação com figuras de força e elegância. Nesse modo, é interessante que as sujeitas identificam que o espaço universitário possa ser um espaço de construção e fortalecimento da autoestima e do reconhecimento da beleza negra em outros corpos e outras formas, Michele Obama e Angela Davis são duas referências muito distintas, temporalmente e politicamente, mas ambas refutam a ideia de que mulheres negras se reduzem a uma sexualidade animalizada e incapacidade da intelectualidade. 
Nesse sentido, as informantes apontam para um padrão de beleza no qual podem se sentir incluídas e bonitas, um padrão de beleza que contemple suas potencialidades: políticas, cientificas, acadêmicas e afetivas; um padrão que tenha como referência a pluralidade e a complexidade de perfis que as mulheres negras apresentam.

\section{CONSIDERAÇÕES FINAIS}

0 processo de discriminação às mulheres negras, em espaços médios, parece perdurar, ainda que elas sejam mulheres "educadas" ou "bem vestidas": ora rechaçadas como objeto de desejo, ora compreendidas como uma beleza sexual, tipo "exportação" (GONZALES, 1983). Por outro lado, elas parecem estar construindo outras respostas ao racismo patriarcal brasileiro. Ao que os trechos apontados acima indicam; essas jovens não têm aceitado ser vistas e reconhecidas, apenas, pelo lugar da beleza exótica, mas, sobretudo, como produtoras de conhecimento sobre si e sobre o mundo; vide a identificação com Angela Davis, por exemplo.

Do mesmo modo, a facilidade de se envolver com sujeitos brancos em espaços da classe média - o que se desdobra em relacionamentos inter-raciais - aponta para uma fragilidade no campo do desejo sexual das mulheres negras. Precisamos pensar e construir caminhos que tornem a autorreflexão das mulheres negras uma potência crítica no campo do desejo e não amarras que prescrevam limitações a sua capacidade de escolher o melhor para si.

Ao mesmo tempo, o reconhecimento de que hábitos diversos da vida - incluindo os gostos musicais - encontram-se marcados por referências e histórias raciais; fortalece essas mulheres na defesa de suas escolhas afro-referenciadas, bem como as potencializam para o confronto de ideias. Algo que parece ser facilitado pelo debate das ações afirmativas na universidade.
Maria: [...] Eu vejo que eu estou ganhando espaço. Eu vejo que... é engraçado, eu vejo como um grupo assim. Eu faço parte de um grupo e esse grupo está crescendo. Mesmo que eu não tenha entrado por cota, mesmo que eu ainda não tenha utilizado cota. Eu vejo os trabalhos de ações afirmativas, eu me sinto mais forte.

Para além da perspectiva da naturalização/desumanização imposta pela sociedade branca hegemônica; existem outras práticas sociais, outros processos educativos e outras formas de desenvolver a subjetividade que estão em curso no país (NOGUEIRA, 2014). A ressignificação da universidade e de lugares economicamente privilegiados - a partir de práticas de conhecimento e cultura enegrecidas - parecem ser uma dessas possíveis saídas em direção a uma sociedade compromissada com o antirracismo e com a construção de lugares mais humanizantes para as mulheres negras.

\section{REFERÊNCIAS}

\section{BENTO, Maria Aparecida Silva. Pactos narcísicos}

no racismo: branquitude e poder nas organizações empresariais e no poder público. 2002. Tese (Doutorado) - Instituto de Psicologia, Universidade de São Paulo, 2002.

\section{BORGES, Larissa Amorim. Nas periferias do}

gênero: uma mirada psicossocial feminista sobre a experiência de mulheres jovens participantes do Hip Hop e do Funk. 2013.

\section{CARNEIRO, Sueli. Mulheres em movimento. Estudos} avançados, v.17, n. 49, p.117-133, 2003.

CARVALHO, Isabel Cristina Moura. Biografia, identidade e narrativa: elementos para uma análise hermenêutica. Horizontes antropológicos, v.9, n.19, p.283-302, 2003.

CORRÊA, Mariza. Sobre a invenção da mulata. Cadernos Pagu, 2010. 
CRENSHAW, Kimberle. A intersecionalidade na discriminação de raça e gênero. VV. AA.

Cruzamento: raça e gênero. Brasília: Unifem, 2004.

DAVIS, Angela. Mulheres, raça e classe. Boitempo Editorial, 2016.

FERES JR, João; DAFLON, Verônica Toste. Ação afirmativa na Índia e no Brasil: um estudo sobre a retórica acadêmica. Sociologias, v.17, n.40, 2015.

FIGUEIREDO, Angela. Novas elites de cor: estudo sobre os profissionais liberais negros de Salvador. Annablume, 2002.

FIGUEIREDO, Angela. Fora do jogo. Cadernos Pagu, v.23, p.199-228, 2004.

FIGUEIREDO, A. Classe média negra: trajetórias e perfis. Salvador: EDUFBA, 2012.

FIGUEIREDO, Ângela; FURTADO, Cláudio Alves. As elites negras. In: SANSONE, Livio; FURTADO, Cláudio Alves. (Org.). Dicionário crítico das ciências sociais dos países de fala oficial portuguesa, Salvador, EDUFBA, 2014. p.131-149.

FONTE, Carla A. A narrativa no contexto da ciência psicológica sob o aspecto do processo de construção de significados. Psicologia: teoria e prática, v.8, n.2, p.123-131, 2006.

GONZAGA, Paula Rita Bacellar. Eu quero ter esse direito a escolha: formações discursivas e itinerários abortivos em Salvador. 2015. Dissertação (Mestrado) - Faculdade de Filosofia e Ciências Humanas, Universidade Federal da Bahia, Salvador, 2015.

GONZALEZ, Lélia. Racismo e sexismo na cultura brasileira. Ciências sociais hoje, v.2, p.223-244, 1983.

HOOKS, Bell. Intelectuais Negras. Estudos

Feministas, Florianópolis, v.3, n.2, p.464, jan. 1995.
Disponível em: <https://periodicos.ufsc.br/index.php/ ref/article/view/16465>. Acesso em: 8 jun. 2017.

LEAL, Luan Ferreira; TROTTA, Felipe. O samba e suas fronteiras: "pagode romântico" e "samba de raiz" nos anos 1990. Rio de Janeiro:UFRJ. Primeiros Estudos, n.3, p.138-142, 2012.

MAYORGA, Claudia. Algunas contribuciones del feminismo a la psicología social comunitaria. Athenea Digital. Revista de pensamiento e investigación social, v. 14, n. 1, p. 221-236, 2014.

MEDEIROS, Janaína. Funk carioca: crime ou cultura? O som dá medo e prazer. São Paulo: Terceiro Nome, 2006.

NOGUEIRA, S.G. Políticas de Identidade, Branquitude e pertencimento étnico-racial. Identidade, Branquitude e Negritude - Contribuições para a psicologial social no Brasil: novos ensaios, relatos de experiência e de pesquisa. São Paulo: Casa do Psicólogo, 2014.

PACHECO, Ana Cláudia Lemos. Mulher negra: afetividade e solidão. Salvador: EDUFBA, 2013.

SANTANA, Ivo de. Negros em colarinhos brancos: estilos de vida, identidades e ascensão social no serviço público1. Cadernos de Estudos Sociais, v.1, n.29, 2014.

SANTOS, Emanuelle; SCHOR, Patricia. Brasil, estudos pós-coloniais e contracorrentes análogas: entrevista com Ella Shohat e Robert Stam. Revista Estudos Feministas, v.21, n.2, p.701-726, 2013.

SCHUCMAN, Lia Vainer. Entre o encardido, o branco e o branquíssimo: raça, hierarquia e poder na construção da branquitude paulistana. 2012. Tese (Doutorado) - Universidade de São Paulo, 2012. 
SCOTT, Joan Wallach. Gênero: Uma Categoria Útil para a Análise Histórica. Educação e Realidade, Porto Alegre, v.16, n.2, p. 5-22, jul-dez.1990.

SILVA, Paula et al. Acerca do debate metodológico na investigação feminista. Revista Portuguesa de Ciências do Desporto, v.5, n.3, p.358-370, 2005.
SKIDMORE, Thomas E. Preto no branco: raça e nacionalidade no pensamento brasileiro. São Paulo: Paz e Terra, 2013.

SOUZA, Claudete Alves da Silva. A solidão da mulher negra: sua subjetividade e seu preterimento pelo homem negro na cidade de São Paulo. 2008. 